$5-1-2013$

\title{
Common peroneal nerve palsy following total hip arthroplasty: prognostic factors for recovery.
}

\author{
Jai Hyung Park \\ Rothman Institute Orthopaedics, Thomas Jefferson University Hospital \\ Bryan Hozack \\ Rothman Institute Orthopaedics, Thomas Jefferson University Hospital \\ Peter Kim \\ Rothman Institute Orthopaedics, Thomas Jefferson University Hospital \\ Robert Norton \\ Rothman Institute Orthopaedics, Thomas Jefferson University Hospital \\ Steven Mandel \\ Rothman Institute Orthopaedics, Thomas Jefferson University Hospital \\ Follow this and additional works at: https://jdc.jefferson.edu/rothman_institute \\ Part of the Orthopedics Commons

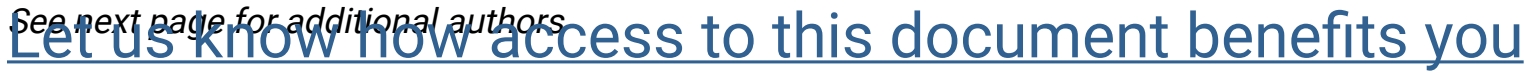

\section{Recommended Citation}

Park, Jai Hyung; Hozack, Bryan; Kim, Peter; Norton, Robert; Mandel, Steven; Restrepo, Camilo; and Parvizi, Javad, "Common peroneal nerve palsy following total hip arthroplasty: prognostic factors for recovery." (2013). Rothman Institute Faculty Papers. Paper 27.

https://jdc.jefferson.edu/rothman_institute/27

This Article is brought to you for free and open access by the Jefferson Digital Commons. The Jefferson Digital Commons is a service of Thomas Jefferson University's Center for Teaching and Learning (CTL). The Commons is a showcase for Jefferson books and journals, peer-reviewed scholarly publications, unique historical collections from the University archives, and teaching tools. The Jefferson Digital Commons allows researchers and interested readers anywhere in the world to learn about and keep up to date with Jefferson scholarship. This article has been accepted for inclusion in Rothman Institute Faculty Papers by an authorized administrator of the Jefferson Digital Commons. For more information, please contact: JeffersonDigitalCommons@jefferson.edu. 


\section{Authors}

Jai Hyung Park, Bryan Hozack, Peter Kim, Robert Norton, Steven Mandel, Camilo Restrepo, and Javad Parvizi 


\title{
Common Peroneal Nerve Palsy Following Total Hip Arthroplasty: Prognostic Factors for Recovery
}

\author{
Jai Hyung Park, MD, PhD, Bryan Hozack, BA, Peter Kim, BS, Robert Norton, MD, Steven Mandel, MD, \\ Camilo Restrepo, MD, and Javad Parvizi, MD, FRCS \\ Investigation performed at Thomas Jefferson University Hospital, Philadelphia, Pennsylvania
}

\begin{abstract}
Background: Common peroneal nerve palsy, although rare, is a serious complication of total hip arthroplasty. Although several publications have dealt with the risk factors for peroneal nerve palsy, there is little literature regarding the time it takes for the nerve to recover and the factors that influence its recovery. The purpose of this study was to elucidate the clinical course of this injury and identify prognostic factors for recovery.
\end{abstract}

Methods: From January 2000 to December 2007, 7969 primary and 1601 revision total hip arthroplasties were performed at our institution. Common peroneal nerve palsy developed following thirty-one $(0.32 \%)$ of these procedures. Thirty of these patients were evaluated by a neurologist at the time of diagnosis and at regular intervals thereafter. Univariate and multivariate regression analyses were performed to identify risk factors and prognostic factors for recovery.

Results: On average, patients who developed common peroneal nerve palsy were significantly younger (fifty-six years) than those who did not develop palsy (sixty-three years, $p<0.05$ ). Higher body mass index (BMI) was a negative prognostic factor for recovery from palsy $(p<0.05)$. The palsy was incomplete in twenty-five of the thirty patients, and fourteen of these recovered fully at a mean of 10.3 months (range, 1.0 to 50.0 months). Three of the five patients with complete nerve palsy recovered fully at a mean of 14.5 months (range, 8.0 to 21.0 months).

Conclusions: Only one-half of the patients in the study who developed common peroneal nerve palsy following total hip arthroplasty recovered fully. The mean time to recovery was approximately one year for partial peroneal palsy and one and one-half years for complete palsy. Obesity adversely influenced the nerve recovery.

Level of Evidence: Prognostic Level II. See Instructions for Authors for a complete description of levels of evidence.

$\mathrm{N}$ eurological injury resulting in nerve palsy is a rare but devastating complication of total hip arthroplasty. Like other nerve injuries, common peroneal nerve palsy following total hip arthroplasty can cause permanent functional impairment and disability ${ }^{1,2}$. Because of its anatomical location, the common peroneal division of the sciatic nerve is the nerve that is injured most frequently, with a reported prevalence ranging from $0.3 \%$ to $2.1 \%$, during total hip arthroplasty ${ }^{3-9}$.

Possible causes of injury resulting in common peroneal nerve palsy following total hip arthroplasty are laceration, ischemia, compression, traction, denaturation due to heat, and a combination of these mechanisms. In approximately one-half of patients, the actual etiology of the palsy is unknown ${ }^{2,10}$. An underlying diagnosis of developmental dysplasia of the hip, revision surgery, female sex, excessive leg lengthening, posttraumatic arthritis, and cementless femoral fixation have been identified as risk factors in previous studies ${ }^{2-5,8,9}$. However, there is little published information to help determine the course of recovery of the nerve and the factors that influence its recovery. In the present study, we retrospectively examined our institution's experience with patients who developed common peroneal nerve palsy following total hip arthroplasty during an eight-year period. The goal of this study was to elucidate more fully the clinical course of this injury and identify risk factors and prognostic factors for recovery.

Disclosure: None of the authors received payments or services, either directly or indirectly (i.e., via his or her institution), from a third party in support of any aspect of this work. One or more of the authors, or his or her institution, has had a financial relationship, in the thirty-six months prior to submission of this work, with an entity in the biomedical arena that could be perceived to influence or have the potential to influence what is written in this work. No author has had any other relationships, or has engaged in any other activities, that could be perceived to influence or have the potential to influence what is written in this work. The complete Disclosures of Potential Conflicts of Interest submitted by authors are always provided with the online version of the article. 
TABLE I Association of Potential Risk Factors with Palsy

\begin{tabular}{|lccc|}
\hline \multicolumn{1}{|c|}{ Variable } & CPNP Group $(\mathrm{N}=30) *$ & Control Group $(\mathrm{N}=90) *$ & P Value \\
\hline Age $(\mathrm{yr})$ & $56.0 \pm 16.9$ & $63.4 \pm 14.0$ & 0.0282 \\
BMI $\left(\mathrm{kg} / \mathrm{m}^{2}\right)$ & $28.9 \pm 7.0$ & $29.4 \pm 6.4$ & 0.7794 \\
Estimated blood & $339.6 \pm 212.5$ & $314.8 \pm 166.7$ & 0.5342 \\
loss $(\mathrm{mL})$ & $3.2 \pm 7.9$ & $2.2 \pm 5.1$ & 0.3594 \\
Leg lengthening $(\mathrm{mm})$ & $91.0 \pm 47.5$ & $77.2 \pm 34.8$ & 0.1074 \\
Operative time $(\mathrm{min})$ & & & \\
\hline
\end{tabular}

*The values are given as the mean and the standard deviation. CPNP $=$ common peroneal nerve palsy.

\section{Materials and Methods}

Crom January 2000 to December 2007, 7969 consecutive primary and 1601 Fevisions total hip arthroplasties were performed at our institution. After institutional review board approval, we retrospectively reviewed the total hip arthroplasty joint registry at our institution and identified common peroneal nerve palsy in thirty-one patients $(0.32 \%)$. One of these patients was excluded because she had prior hemiplegia due to a stroke on the same side as the total hip arthroplasty. The medical records of the remaining thirty patients were reviewed in detail to extract relevant information.

\section{Demographics}

Eighteen of the patients $(60 \%)$ were female and twelve (40\%) were male. The mean age at the time of surgery was fifty-six years (range, sixteen to eighty-three years). The mean body mass index (BMI) was $28.9 \mathrm{~kg} / \mathrm{m}^{2}$ (range, 19.2 to 47.5 $\mathrm{kg} / \mathrm{m}^{2}$ ). The palsy occurred following primary total hip arthroplasty in twentysix patients and revision total hip arthroplasty in four patients. The preoperative diagnoses included osteoarthritis in twenty patients $(66 \%)$, osteonecrosis of the femoral head in two (7\%), juvenile rheumatoid arthritis in one $(3 \%)$, arthritis secondary to developmental dysplasia of the hip in one $(3 \%)$, posttraumatic arthritis in two (7\%), and revision surgery in four (13\%).

All patients had had normal motor nerve function (grade 5 of 5 ) and sensory nerve function preoperatively. Spinal anesthesia was used in twentyeight patients (93\%) and general anesthesia was used in two (7\%). A modified direct lateral (Hardinge) approach was used in all patients. All patients received uncemented acetabular and femoral components. The mean operative time was ninety-one minutes (range, forty-five to 200 minutes). The mean estimated blood loss was $340 \mathrm{~mL}$ (range, 100 to $900 \mathrm{~mL}$ ).

Injuries were stratified as complete or incomplete on the basis of an evaluation by the neurologist. Complete neurological injury was defined as grade 0 of 5 muscle strength (no motor function); patients with incomplete injury demonstrated grade 1 of 5 muscle strength or better (some motor function $)^{4,11}$. Sixteen $(53 \%)$ of the thirty injuries resulting in common peroneal nerve palsy occurred on the left side and fourteen (47\%) on the right.

\section{Follow-up}

Patients were followed for a minimum of two years unless full recovery of the nerve occurred earlier. The mean duration of follow-up was 44.3 months

TABLE II Effect of BMI on Recovery

\begin{tabular}{|lll|}
\hline Recovery & No. & BMI* $\left(\mathrm{kg} / \mathrm{m}^{2}\right)$ \\
\hline Full & 17 & $24.9 \pm 5.11$ \\
Partial & 13 & $33.0 \pm 6.57$ \\
\hline
\end{tabular}

*The values are given as the mean and the standard deviation. (range, 3.7 to 114.4 months). During the follow-up visits, each patient was examined by his or her surgeon and the extent of neurological recovery, functional status, and use of medications for neurological symptoms were evaluated. Limb-length discrepancy was also assessed during the preoperative and postoperative visits by means of physical examinations and radiographs. The decision to perform magnetic resonance imaging (MRI), computed tomography (CT) scanning, or electromyography (EMG) was based on the clinical judgment of the attending surgeon or consulting neurologist.

\section{Statistical Analysis}

Multivariate logistic regression analysis (with use of 95\% confidence intervals [CIs]) was performed to assess sex, age, race, BMI, and underlying diagnosis as possible risk factors for the development of common peroneal nerve palsy. Patients with palsy were matched in a 1:3 ratio with control patients without palsy on the basis of the year of surgery, type of surgery, mode of implant fixation (which was uncemented in all patients in the cohort with palsy), and surgeon. The two cohorts were then compared to identify potential risk factors. In order to identify prognostic factors for recovery, univariate and multivariate logistic regression analyses were performed to assess sex, age, BMI, possible etiology, motor nerve involvement, time of onset, and extent of initial injury. Patients with full recovery were matched with patients with partial recovery.

A p value of $<0.05$ was considered significant in all analyses.

\section{Source of Funding}

No external funding was received for this investigation.

\section{Results}

Cour (13\%; 95\% CI, $1 \%$ to $25 \%$ ) of the thirty patients with common peroneal nerve palsy also had tibial nerve involvement, with weakness in plantar flexion. Twelve patients $(40 \%$; $95 \%$ CI, $22 \%$ to $58 \%$ ) were diagnosed on the day of surgery; nine $(30 \%$; $95 \% \mathrm{CI}, 14 \%$ to $46 \%)$, on postoperative day 1 ; six (20\%; $95 \%$ CI, $6 \%$ to $34 \%$ ), on day 2 ; two $(7 \%$; $95 \%$ CI, $0 \%$ to $16 \%)$, on day 3 ; and one (3\%; $95 \%$ CI, $0 \%$ to $10 \%)$, on day 7 . Motor and sensory function were both affected in twenty-four patients $(80 \%$; $95 \% \mathrm{CI}, 66 \%$ to $94 \%)$, motor function alone was affected in four (13\%; 95\% CI, $1 \%$ to $25 \%)$, and sensory function alone was affected in two (7\%; 95\% CI, $0 \%$ to $16 \%)$. The palsy was considered to be incomplete in twenty-five patients $(83 \% ; 95 \% \mathrm{CI}, 71 \%$ to $97 \%)$ and complete in the remaining five (17\%; 95\% CI, 3\% to $30 \%)$. Fourteen (56\%; 95\% $\mathrm{CI}, 37 \%$ to $75 \%$ ) of the twenty-five patients with incomplete nerve palsy recovered fully at a mean of 10.3 months (range, 1.0 to 50.0 months), and three (95\% CI, 17\% to $100 \%$ ) of the five 
The Journal of Bone \& Joint Surgery $\cdot$ Jbjs.org Volume 95-A · Number 9 - May 1, 2013
Common Peroneal Nerve Palsy Following Total Hip Arthroplasty: Prognostic Factors for Recovery patients with complete nerve palsy recovered fully at a mean of 14.5 months (range, 8.0 to 21.0 months). The suspected etiology of the palsy was determined on the basis of a complete evaluation by a neurologist as well as cross-sectional imaging (CT or MRI) in fourteen patients and EMG in eight. The etiology involved compression in nine patients $(30 \% ; 95 \% \mathrm{CI}$, $14 \%$ to $46 \%$ ), with the cause of the compression being a hematoma in six patients (95\% CI, 6\% to 34\%), an acetabular screw in one ( $95 \% \mathrm{CI}, 0 \%$ to $10 \%$ ), a preexisting lipoma in one ( $95 \% \mathrm{CI}, 0 \%$ to $10 \%$ ), and direct compression at the level of the fibular head due to positioning in one (95\% CI, $0 \%$ to $10 \%$ ). The etiology involved traction in seven patients $(23 \%$; $95 \% \mathrm{CI}$, $8 \%$ to $38 \%$ ), with the traction resulting from retractor placement in four patients $(13 \% ; 95 \% \mathrm{CI}, 1 \%$ to $25 \%)$, from limblengthening in two $(7 \% ; 95 \% \mathrm{CI}, 0 \%$ to $16 \%)$, and from dislocation in one $(3 \% ; 95 \% \mathrm{CI}, 0 \%$ to $10 \%)$. The etiology was unknown in the remaining fourteen patients $(47 \% ; 95 \% \mathrm{CI}$, $29 \%$ to $65 \%$ ). The mean change in limb length in the palsy cohort was an increase of $3.2 \mathrm{~mm}$ (range, 0 to $25 \mathrm{~mm}$ ). The two patients $(7 \%$; $95 \% \mathrm{CI}, 0 \%$ to $16 \%)$ in whom this was considered to represent limb lengthening had $6 \mathrm{~mm}$ and $25 \mathrm{~mm}$ of lengthening. Exploration was carried out in three patients; two of these patients underwent evacuation of a hematoma and the third underwent a revision procedure to remove an acetabular screw. The latter patient had almost complete motor nerve palsy following her initial surgery, and her CT scan demonstrated possible sciatic nerve compression by the acetabular screw. After screw removal, the motor and sensory function in this patient returned.
There was a trend, although not significant, toward increased operative time in the patients with palsy (ninety-one minutes) compared with matched controls without palsy (seventy-seven minutes, $\mathrm{p}=0.11$ ). The mean blood loss in the patients with palsy was $340 \mathrm{~mL}$, which was not significantly different from that in patients who did not develop palsy following total hip arthroplasty $(315 \mathrm{~mL}, \mathrm{p}=0.53)$. The limb lengthening in the patients with palsy was not significantly different from that in the matched controls without postoperative palsy (mean, $2.2 \mathrm{~mm}$; range, 0 to $30 \mathrm{~mm}$; $\mathrm{p}=0.4$ ). A significant difference was seen only in the mean age; on average, the patients with palsy were younger (fifty-six years) than those without palsy (sixty-three years, $\mathrm{p}<0.05$ ) (Table I).

Three (95\% CI, $17 \%$ to $100 \%)$ of the five patients whose initial injury was complete and fourteen (56\%; 95\% CI, 37\% to $75 \%$ ) of the twenty-five patients with an incomplete injury had full recovery. One (95\% CI, $0 \%$ to $100 \%)$ of the two patients in whom a motor nerve was not involved and sixteen (57\%; 95\% $\mathrm{CI}, 39 \%$ to $75 \%$ ) of the twenty-eight patients with motor nerve involvement had full recovery. The univariate and multivariate logistic regression analyses showed that BMI influenced recovery. Patients with full recovery had a significantly lower mean BMI of $24.9 \mathrm{~kg} / \mathrm{m}^{2}$ (range, 19.2 to $36.4 \mathrm{~kg} / \mathrm{m}^{2}$ ) compared with $33.0 \mathrm{~kg} / \mathrm{m}^{2}$ (range, 24.6 to $47.5 \mathrm{~kg} / \mathrm{m}^{2}$ ) in the patients without full nerve recovery $(\mathrm{p}=0.0054)$ (Table II).

The crude risk of common peroneal nerve palsy among all patients undergoing primary or revision total hip arthroplasty was stratified by BMI in increments of $5 \mathrm{~kg} / \mathrm{m}^{2}$ (Fig. 1). The risk of palsy was $0.24 \%$ (95\% CI, $0 \%$ to $0.7 \%$ ) for the BMI

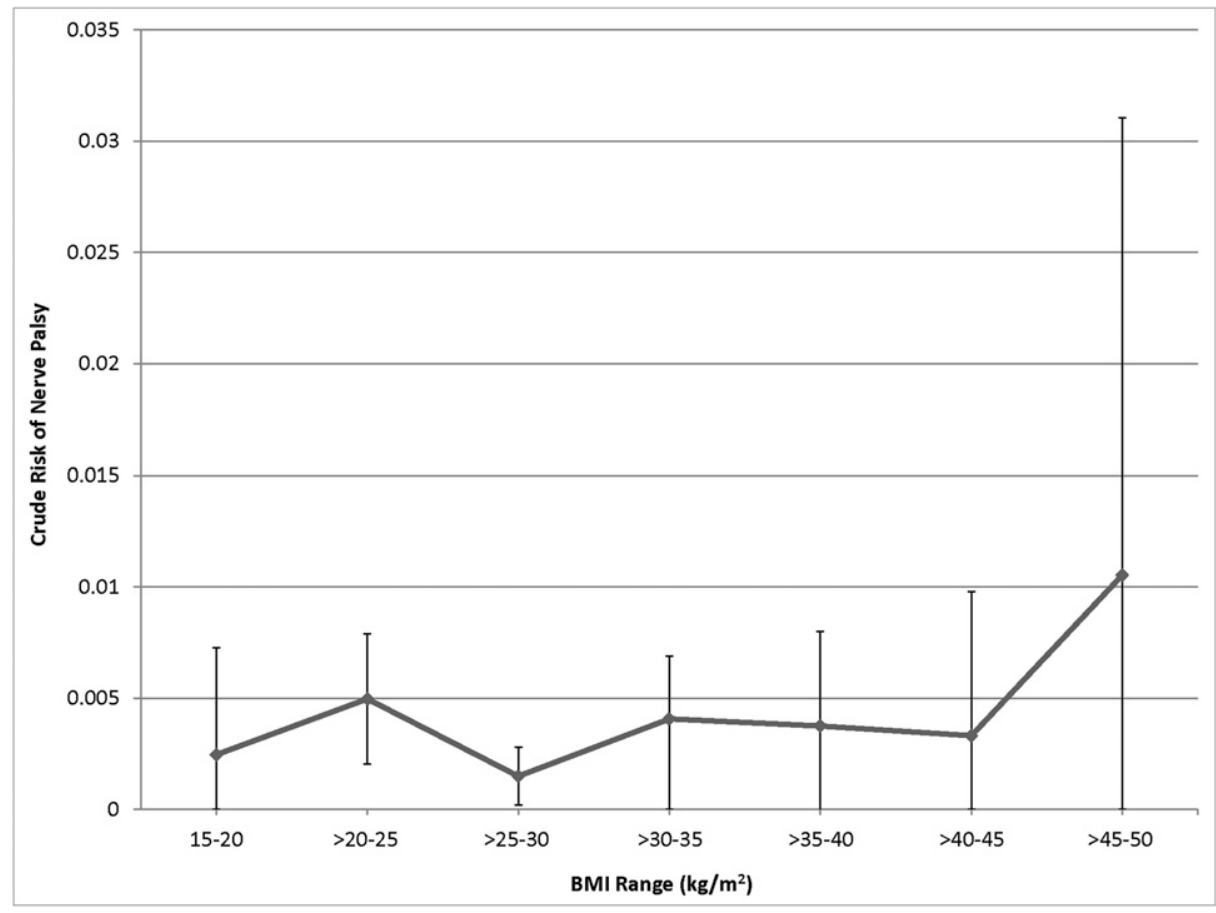

Fig. 1

Risk of common peroneal nerve palsy according to BMI. The error bars indicate the $95 \% \mathrm{Cl}$. 
The Journal of Bone \& Joint Surgery $\cdot$ Jbjs.org Volume 95-A · Number 9 - MAY 1, 2013
Common Peroneal Nerve Palsy following Total Hip Arthroplasty: Prognostic Factors for Recovery range of 15 to $20 \mathrm{~kg} / \mathrm{m}^{2}, 0.50 \%$ ( $95 \% \mathrm{CI}, 0.2 \%$ to $0.8 \%$ ) for $>20$ to $25 \mathrm{~kg} / \mathrm{m}^{2}, 0.2 \%$ (95\% CI, $0.02 \%$ to $\left.0.3 \%\right)$ for $>25$ to $30 \mathrm{~kg} / \mathrm{m}^{2}$, $0.41 \%$ (95\% CI, $0.01 \%$ to $0.7 \%$ ) for $>30$ to $35 \mathrm{~kg} / \mathrm{m}^{2}, 0.38 \%$ ( $95 \%$ CI, $0 \%$ to $0.8 \%$ ) for $>35$ to $40 \mathrm{~kg} / \mathrm{m}^{2}, 0.33 \%(95 \% \mathrm{CI}$, $0 \%$ to $1 \%$ ) for $>40$ to $45 \mathrm{~kg} / \mathrm{m}^{2}$, and $1.05 \%$ (95\% CI, $0 \%$ to $3 \%$ ) for $>45$ to $50 \mathrm{~kg} / \mathrm{m}^{2}$. No single BMI range in this study was associated with a significantly elevated risk of palsy.

Five of the patients were prescribed gabapentin for the treatment of the neuropathic symptoms. The drug provided some improvement in symptoms for one patient and was not effective for the others. None of the patients required long-term pain medication. At the time of the latest follow-up, twenty-three patients were able to walk without difficulty, five were able to walk with the use of an ankle-foot orthosis, and two required the use of a walking aid.

\section{Discussion}

$\mathrm{C}$ ommon peroneal nerve palsy following total hip arthroplasty is a rare complication that has a poorly understood clinical course. The prevalence of this injury in the present study was $0.32 \%$ ( $95 \%$ CI, $0.2 \%$ to $0.4 \%$ ), which is consistent with previously reported prevalences of $0.3 \%$ to $2.1 \%{ }^{2-9}$. The variability in the prevalence of nerve palsy among studies can likely be attributed to variability in the patient populations, indications for surgery, and rigor in diagnosis. Even though the reported prevalence of common peroneal nerve palsy is relatively low, a substantial number of patients with subclinical palsy (palsy that is asymptomatic or not reported to their doctor) go unrecognized. Weale et al. demonstrated that clinical diagnosis alone underestimates the presence of nerve injury, whereas EMG studies have suggested that the prevalence of subclinical common peroneal nerve injury following total hip arthroplasty may be $>70 \%{ }^{11,12}$. Our data revealed a prevalence of clinically relevant common peroneal nerve palsy similar to that in previous reports, but we recognize that many additional patients may have had a subtle nerve injury that were not diagnosed.

Sunderland reported that the sciatic nerve exited the pelvis as two distinct nerves in approximately $30 \%$ of the cadavers that were studied ${ }^{13}$. In such cases, the tibial division generally enters the gluteal region distal to the piriformis muscle, whereas the peroneal division may enter proximal to or through the piriformis. Also, the peroneal nerve is the more lateral portion, is more superficial, and is relatively fixated at the sciatic notch. When palsy occurs, the peroneal portion of the common peroneal nerve is more likely to be affected for several reasons. The peroneal nerve, with a few large funiculi, has only sparse connective tissue, thus restricting the ability of the nerve to elongate. In contrast, the tibial nerve, with relatively smaller funiculi, has more connective tissue that allows it to sustain a much greater elongation without permanent neural damage $^{14-16}$. Most of the cases of common peroneal nerve palsy reported in the literature appear to be related to causes such as traction from leg lengthening, compression from a hematoma, retractor placement, limb positioning during femoral preparation, thermal damage, or nerve impingement by bone cement. In addition, direct laceration of the nerve may occur as a result of penetration of the femoral cortex during reaming, and damage may be caused by a suture or wire $e^{2-5,8,9,17}$. Although the suspected nerve palsy etiologies in our series were similar to those in previous reports, the cause could not be determined in nearly one-half of the patients. This is also consistent with the literature, in which the cause of the palsy was not identified in approximately $50 \%$ of patients ${ }^{2,10}$.

This study has some limitations. First, it was conducted at a single institution and the findings may not be generalizable to all patients with common peroneal nerve palsy. We perform total hip arthroplasty with the patient in the supine position and with use of an anterolateral approach, uncemented components, and typically regional anesthesia. Thus, some etiological and possibly prognostic factors may not have been identified because of these homogeneities in our patient population. Second, the retrospective nature of the study may introduce bias as a result of possible variability in the recording of the clinical course and subsequent data collection. Finally, despite the relatively large size of the cohort of patients with common peroneal nerve palsy, some factors influencing recovery may not have been identified by the multivariate analysis because of their low prevalence, resulting in a type-II error.

One strength of the study is the fact that all patients were evaluated by a neurology team with expertise in peripheral nerve palsy and underwent extensive investigations postoperatively to elucidate the etiology of the palsy. Furthermore, these patients were followed closely by both the surgeon and the neurology team for a minimum of two years or until nerve palsy recovery (which resulted in some patients having a short follow-up because of their recovery). The clinical course of any recovery was documented in detail in the clinical records. Although many risk factors for this injury have been investigated and various associations have been observed ${ }^{2-5,8,9}$, it has always been difficult to ascertain the true risk factors with certainty. Even though leg lengthening is a well-documented cause of common peroneal nerve palsy, the mean leg lengthening in the patients at our institution who developed palsy was not significantly greater than that in the matched control patients who did not develop palsy. There was a trend, although not significant, toward increased operative time in patients who developed common peroneal nerve palsy following total hip arthroplasty. The increased operative time may reflect technical difficulties and indicate the effects of compression or tension on the nerve.

A previous study by Schmalzried et al. suggested that the severity of the initial injury may influence the outcome of the nerve palsy ${ }^{17,18}$. Those authors found a significant relationship between normal recovery of function and the initial retention of some motor function. None of their patients who had severe dysesthesia had good recovery of neurological func$\operatorname{tion}^{17,18}$. In our study, the only factor related to the prognosis was BMI, with a higher BMI increasing the chance of incomplete recovery. Motor nerve involvement was not significantly associated with full recovery, although only two patients had a pure sensory nerve injury. Also, the initial completeness of the nerve injury was not related to full recovery. Edwards et al. 
The Journal of Bone \& Joint Surgery - Jbjs.org Volume 95-A · Number 9 - MAY 1, 2013
Common Peroneal Nerve Palsy following Total Hip Arthroplasty: Prognostic Factors for Recovery concluded that there was less residual disability in patients with common peroneal nerve palsy caused by direct compression injury than in patients with a stretch injury ${ }^{10}$. However, experimental models have shown that peripheral nerves are especially vulnerable to compression ${ }^{19,20}$. In our study, there was no difference between etiologies involving compression and stretching with regard to the prognosis. Although it is difficult to establish the cause and effect of primary vascular injury, as pointed out by Sunderland, the inferior gluteal, medial femoral circumflex, and perforating arteries of the profunda femoris provide a rich supply of nutrient arterioles to the sciatic nerve ${ }^{13}$. Therefore, dissection of the short external rotators and mobilization of the sciatic nerve during exposure could interfere with adequate collateralization in a posterior surgical approach. In our study, the posterior approach was not used. Edwards et al. found that, at a minimum of one year following total hip arthroplasty, only three $(16 \%)$ of nineteen patients had recovered completely, eleven (58\%) had a mild deficit, and five $(26 \%)$ had a major deficit ${ }^{10}$. In a study by Schmalzried et al., twenty-nine $(81 \%)$ of thirty-six patients who had been followed for a minimum of two years had a persistent neurological deficit $^{17}$. In our study, fourteen (56\%; 95\% CI, 37\% to 75\%) of the twenty-five patients with incomplete nerve palsy recovered fully at a mean of 10.3 months and three (95\% CI, $17 \%$ to $100 \%$ ) of the five patients with complete nerve palsy recovered fully at a mean of 14.5 months. Although the number of pa- tients with common peroneal nerve palsy following total hip arthroplasty was not enough to predict recovery, our retrospective study identified not only risk factors but also prognostic factors. Only 57\% (95\% CI, 39\% to 74\%) of the patients who developed palsy following total hip arthroplasty recovered fully. The mean time to recovery was approximately one year for incomplete palsy and one and one-half years for complete palsy. The recovery rate did not appear to differ between patients with complete and incomplete palsy or between patients with and without motor nerve involvement. Patients with a lower BMI were much more likely to experience full recovery of the nerve.

Jai Hyung Park, MD, PhD

Bryan Hozack, BA

Peter Kim, BS

Robert Norton, MD

Steven Mandel, MD

Camilo Restrepo, MD

Javad Parvizi, MD, FRCS

Rothman Institute Orthopaedics (J.H.P., B.H., P.K., R.N., C.R., J.P.) and Department of Neurology (S.M.), Thomas Jefferson University Hospital, 925 Chestnut Street, 2nd Floor, Philadelphia, PA 19107.

E-mail address for J. Parvizi: research@rothmaninstitute.com

\section{References}

1. Ahmad I, Patil S. Isolated deep peroneal (fibular) nerve palsy in association with primary total hip arthroplasty. Clin Anat. 2007 Aug;20(6):703-4.

2. Brown GD, Swanson EA, Nercessian OA. Neurologic injuries after total hip arthroplasty. Am J Orthop (Belle Mead NJ). 2008 Apr;37(4):191-7.

3. Eftekhar NS, Stinchfield FE. Experience with low-friction arthroplasty. A statistical review of early results and complications. Clin Orthop Relat Res. 1973 Sep;(95):60-8.

4. Farrell CM, Springer BD, Haidukewych GJ, Morrey BF. Motor nerve palsy following primary total hip arthroplasty. J Bone Joint Surg Am. 2005 Dec;87(12):2619-25.

5. Lazansky MG. Complications revisited. The debit side of total hip replacement Clin Orthop Relat Res. 1973 Sep;(95):96-103.

6. Moczynski G, Abraham E, Barmada R, Ray RD. Evaluation of total hip replacement arthroplasties. Clin Orthop Relat Res. 1973 Sep;(95):213-6.

7. Murray WR. Results in patients with total hip replacement arthroplasty. Clin Orthop Relat Res. 1973 Sep;(95):80-90.

8. Navarro RA, Schmalzried TP, Amstutz HC, Dorey FJ. Surgical approach and nerve palsy in total hip arthroplasty. J Arthroplasty. 1995 Feb;10(1):1-5.

9. Nercessian OA, Macaulay W, Stinchfield FE. Peripheral neuropathies following total hip arthroplasty. J Arthroplasty. 1994 Dec;9(6):645-51.

10. Edwards BN, Tullos HS, Noble PC. Contributory factors and etiology of sciatic nerve palsy in total hip arthroplasty. Clin Orthop Relat Res. 1987 May;(218): 136-41.
11. Weale AE, Newman P, Ferguson IT, Bannister GC. Nerve injury after posterior and direct lateral approaches for hip replacement. A clinical and electrophysiological study. J Bone Joint Surg Br. 1996 Nov;78(6):899-902.

12. Weber ER, Daube JR, Coventry MB. Peripheral neuropathies associated with total hip arthroplasty. J Bone Joint Surg Am. 1976 Jan;58(1):66-9.

13. Sunderland S. Blood supply of the sciatic nerve and its popliteal divisions in man. Arch Neurol Psychiatry. 1945 Oct;54:283-9.

14. Chiba S. [Multiple positional relationships of nerves arising from the sacral plexus to the piriformis muscle in humans]. Kaibogaku Zasshi. 1992 Dec;67(6):691-724.

15. DeHart MM, Riley LH Jr. Nerve injuries in total hip arthroplasty. J Am Acad Orthop Surg. 1999 Mar-Apr;7(2):101-11.

16. Hurd JL, Potter HG, Dua V, Ranawat CS. Sciatic nerve palsy after primary total hip arthroplasty: a new perspective. J Arthroplasty. 2006 Sep;21(6):796-802.

17. Schmalzried TP, Amstutz HC, Dorey FJ. Nerve palsy associated with total hip replacement. Risk factors and prognosis. J Bone Joint Surg Am. 1991 Aug; 73(7):1074-80.

18. Schmalzried TP, Noordin S, Amstutz HC. Update on nerve palsy associated with total hip replacement. Clin Orthop Relat Res. 1997 Nov;(344):188-206.

19. Johanson NA, Pellicci PM, Tsairis $P$, Salvati EA. Nerve injury in total hip arthroplasty. Clin Orthop Relat Res. 1983 Oct;(179):214-22.

20. Solheim LF, Hagen R. Femoral and sciatic neuropathies after total hip arthroplasty. Acta Orthop Scand. 1980 Jun;51(3):531-4. 